\title{
Review \\ Coffee Silverskin: A Review on Potential Cosmetic Applications
}

\author{
Sílvia M. F. Bessada *, Rita C. Alves * (D) and M. Beatriz P. P. Oliveira \\ REQUIMTE/LAQV, Department of Chemical Sciences, Faculty of Pharmacy, University of Porto, 4050-313 Porto, \\ Portugal; beatoliv@ff.up.pt \\ * Correspondence: silviabessada@gmail.com (S.M.F.B.); rita.c.alves@gmail.com (R.C.A.); \\ Tel.: +351-220-428-640 (S.M.F.B. \& R.C.A.)
}

Received: 7 November 2017; Accepted: 28 December 2017; Published: 3 January 2018

\begin{abstract}
Coffee silverskin, the major coffee-roasting by-product, is currently used as fuel and for soil fertilization. However, there are several studies reporting silverskin as a good source of bioactive compounds that can be extracted and further used by cosmetic industry. Its high antioxidant potential may be due to the synergistic interaction of chlorogenic acids (1-6\%), caffeine $(0.8-1.25 \%)$, and melanoidins (17-23\%), among other antioxidant compounds. The bioactive compounds of silverskin can answer to the new fields of cosmetic industry on natural active ingredient resources that improve health skin appearance, counteract skin aging and related diseases, in an environmentally friendly approach. Skin aging is a complex process associated with oxidative metabolism and reactive oxygen species (ROS) generation. ROS production increase matrix metalloproteinases (MMPs), as well as pro-inflammatory mediators, resulting in consequent skin damage and aging. To counteract this process, cosmetic industry is looking for compounds able to increase MMP inhibitory activities, hyaluronidase inhibitory activity, expression of collagen and elastase inhibitory activity, as potential bioactive ingredients with anti-aging purposes. This review focuses on skin aging factors and the potential anti-aging, anti-inflammatory, antimicrobial, anti-cellulite and anti-hair loss activity, as well as protection against UV damage, of coffee silverskin and their bioactive compounds.
\end{abstract}

Keywords: coffee silverskin; by-product; anti-aging; antioxidant; anti-inflammatory; antimicrobial; anti-cellulite; anti-hair loss; skin damage protection

\section{Introduction}

Coffee is the most popular beverage over the world, being its regular consumption highly increasing. The main coffee production is based on two plant species: Coffea arabica and Coffea canephora, also known as arabica and robusta coffees, respectively. Along the several steps of coffee production, a huge amount of residue is generated (e.g., husks, hulls, defective beans, coffee silverskin, and spent coffee grounds). Indeed, coffee wastes and by-products constitute a source of severe contamination and an environmental problem. The chemical characterization of coffee residues and their use as potential bioactive ingredients for development of novel functional products emerge as a factor of environmental sustainability and economic recovery to the companies of coffee processing and roasting. Coffee silverskin (CS) is a thin tegument that directly covers the coffee seed. During the roasting process, coffee beans expand and this thin layer is detached, becoming the main by-product of coffee roasting industries [1]. CS, compared to other coffee by-products, is a relatively stable product due to its lower moisture content (5-7\%) [2,3]. Currently used as fuel, for composting and soil fertilization, CS represents a good source of several bioactive compounds that can be extracted and further used for food, cosmetic and pharmaceutical purposes [4].

CS is composed by a high amount of dietary fiber (56-62\%), especially soluble fiber $(\sim 87 \%)[2,3]$. It contains cellulose $(18 \%)$ and hemicellulose $(13 \%)$, being this last composed by xylose $(4.7 \%)$, 
arabinose $(2.0 \%)$, galactose $(3.8 \%)$, and mannose $(2.6 \%)$ [5]. It is also rich in protein $(19 \%)$ and minerals ( $8 \%$ ash). Mineral composition consists mainly in potassium, magnesium and calcium $(\sim 5 \mathrm{~g}$, $2 \mathrm{~g}$, and $0.5 \mathrm{~g}$ per $100 \mathrm{~g}$ silverskin, respectively) [4]. Fat content varies from $1.6 \%$ to $3.3 \%$, being dependent on the geographical origin of the coffee. Triacylglycerols are the major components $(48 \%)$, followed by free fatty acids $(21 \%)$, esterified sterols $(15 \%)$, free sterols $(13 \%)$, and diacylglycerols $(4 \%)[6,7]$. According to a previous study [4], CS presents mainly saturated fatty acids $(65 \%)$, followed by polyunsaturated $(28 \%)$ and monounsaturated $(7 \%)$ ones. C18:2n6c was the major fatty acid found (24\%), followed by C16:0 (22\%), C22:0 (15\%), and C20:0 (14\%). Regarding antioxidant compounds, Costa et al. [4] analyzed, for the first time, the vitamin E profile of CS, which presents a total content around $4.17 \mathrm{mg} / 100 \mathrm{~g}$. Four tocopherols $(\alpha, \beta, \gamma$, and $\delta)$ and three tocotrienols ( $\beta$, $\gamma$, and $\delta)$ were the vitamers found, being $\alpha$-tocopherol $(2.25 \mathrm{mg} / 100 \mathrm{~g})$ the major one, followed by $\beta$-tocotrienol $(0.95 \mathrm{mg} / 100 \mathrm{~g})$ [4]. Other important bioactive compounds present in CS are chlorogenic acids (1-6\%) (being 5-O-, 3-O- and 4-O-caffeoylquinic acids the most relevant ones), caffeine $(0.8-1.25 \%)$, and Maillard reaction products formed during the roasting process, namely melanoidins (17-23\%). Indeed, chlorogenic acids and their thermal degradation products seem to be involved in the formation of melanoidins, along with others compounds, such as polysaccharides (galactomannans and arabinogalactans) and proteins $[4,8,9]$.

Attending nutritional and chemical composition, antioxidant activity and several bioactive compounds, CS emerges as a particularly interesting product to be used in food, cosmetic and pharmaceutical industries. However, the use of this coffee waste must take into account safety concerns, since CS could contain ochratoxin A (OTA), an Aspergillus ochraceus and Penicillium verrucosum toxin, classified by the International Agency for Research on Cancer (IARC) as a possible human carcinogen. The Commission Regulation (EC) No 123/2005 defined OTA limits as $5 \mu \mathrm{g} / \mathrm{kg}$ for roasted coffee and $10 \mu \mathrm{g} / \mathrm{kg}$ for soluble coffee. For CS, there is no specific OTA regulation limit [10,11]. Some authors have described the effect of coffee roasting (time/temperature) on the reduction of OTA levels (reduction $>90 \%$ ), reporting a level below $4 \mu \mathrm{g} / \mathrm{kg}$ in CS [2,12]. Nevertheless, Toschi et al. [7] quantified OTA levels between 18.7 and $34.4 \mathrm{ug} / \mathrm{kg}$ CS, corresponding to values three times higher than those fixed by the European Commission. The same study also describes the presence of phytosterol oxidation products $(114.11 \mathrm{mg} / 100 \mathrm{~g})$; therefore, it is crucial to set up good practices of production and a rigorous quality control, developing suitable methods to minimize the presence of these undesirable compounds.

Until now, several innovative approaches have been suggested for CS, essentially based on its richness in dietary fiber, phenolic compounds and other antioxidants, such as melanoidins $[2,3,13,14]$. For instance, Mussato et al. [14] suggested its incorporation in flakes, breads, biscuits and snacks. In addition, Pourfarzad et al. [15] used this by-product to improve quality, shelf life, and sensorial properties of Barbari flat bread, while reducing its caloric density and increasing the dietary fiber content. In turn, Martinez-Saez et al. [16] used CS to prepare a novel antioxidant beverage for body weight control, while new approaches on cosmetic uses have been reported by Rodrigues and colleagues $[17,18]$.

Cosmetic industry has been looking for new active ingredients, due to the consumer demand for more natural and environmentally friendly products obtained by sustainable resources that improve health skin appearance. Silverskin is a potential candidate to replace synthetic chemicals as active ingredients in cosmetic formulations due to their high antioxidant potential, phenolic compounds, melanoidins and caffeine contents [19]. Table 1 shows the major CS bioactive compounds that can be extracted for cosmetic purposes, based on their biological activities. 
Table 1. Major CS bioactive compounds and biological activities (Adapted from Rodrigues et al. [19]).

\begin{tabular}{ccc}
\hline Compound & Biological Activities & References \\
\hline Caffeine & $\begin{array}{c}\text { Antioxidant and anti-aging activity; Thermogenic and anti-cellulite } \\
\text { activity; Protection against UV damage; Increase of blood circulation in } \\
\text { the skin; Inhibition of } 5 \alpha \text {-reductase and hyaluronidase activities. }\end{array}$ & {$[7,19,20]$} \\
\hline $\begin{array}{c}\text { Caffeoylquinic acids/ } \\
\text { Feruloylquinic acids/ }\end{array}$ & $\begin{array}{c}\text { Anti-aging activity; Protection against UV damage; Antimicrobial and } \\
\text { anti-inflammatory activity. }\end{array}$ & {$[17,21]$} \\
\hline Melanoidins & Antioxidant, anti-aging, antimicrobial and anti-inflammatory activities. & {$[22]$} \\
\hline
\end{tabular}

\section{Skin Aging and Related Diseases}

Skin, the largest organ of human body, has multiples functions, being the protection against environmental factors one of the most important. As a living organ, skin goes through significant changes throughout a person's lifetime, so the appearance of a luminous visual and a healthy skin, less aged or damaged is a constant consumer requirement and a challenge for cosmetic products. In fact, the search for new and improved multifunctional ingredients from natural sources has been a relevant issue in cosmetic fields.

Aging is defined as an accumulation of changes in the cells, tissues or organs over the time, which leads to a progressive loss of structure and function, an inevitable, universal phenomenon that depends on each person's genetic capital and lifestyle. Skin aging is a slow and complex process including intrinsic and extrinsic mechanisms involved, which induce skin changes as thinning, dryness, laxity, fragility, enlarged pores, fine lines, and wrinkles [23,24]. Intrinsic aging occurs as a natural consequence of human physiological and genetic changes, while extrinsic aging is mainly caused by cumulative exposure to external harmful factors such as UV radiation, atmospheric pollution, and infectious agents that induce alterations and skin damage. Oxidative stress, the major cause of skin accelerated aging and related diseases, can be defined as the imbalance between ROS and reactive nitrogen species (RNS) (e.g., superoxide anion radical, hydroxyl, alkoxyl and lipid peroxyl radicals, nitric oxide and peroxynitrite) and antioxidants. The human body developed a complex endogenous antioxidant system to counteracted "physiologic" oxidative stress, which includes endogenous antioxidant enzymes such as superoxide dismutase, catalase, glutathione peroxidase, and non-enzymatic compounds (e.g., glutathione, proteins, coenzyme $Q$, and lipoic acid), as well as exogenous antioxidants obtained from $\operatorname{diet}$ (vitamin $\mathrm{C}$ and $\mathrm{E}$, carotenoids, phenolic compounds, etc.) [25]. In fact, different species and plant constituents have been chemically characterized as natural sources of antioxidant compounds with a high potential of application [26]. When cells are subjected to excessive levels of oxidants or the depletion of antioxidants, oxidative stress occurs. Under normal conditions, oxidants are natural by-products of physiological processes (e.g., mitochondria, peroxisomes and plasma membrane), which have positive physiological effects on cells, being involved in differentiation, proliferation, and signal transduction. However, reactive species can also be generated by exogenous sources and cause DNA, protein and lipid damages. With age, an imbalance arises between oxidants production and antioxidants (created or ingested), which can lead to skin aging and some related diseases (e.g., dermatitis, sunburn, eczema, vasculitis, cancer, etc.). Indeed, skin aging seems to be associated to oxidative metabolism and reactive species generation $[19,23,27]$.

Keratinized stratified epidermis and an underlying thick layer of collagen-rich dermal connective tissue are important components of the young skin. Summarizing, skin is composed by three important layers: the epidermis keratinization process leads to a thin stratum corneum layer that provide skin protection, which, together with a hydrolipidic film, create a true barrier against external stress; the internal thick layer of skin, dermis, is comprised by water, elastin and collagen fibers, being the supportive tissue; and the hypodermis is the deepest and thickest layer of skin, rich in adipose cells and protects the body from physical shock and temperature variations. It is also an energy reserve [28].

The loss of structural protein (type-1 collagen) in the dermal layer, is the major cause of wrinkle-aging process formation. Indeed, skin aging is related to the reduction of collagen production 
and increased levels of matrix metalloproteinases (MMP), mostly MMP-1 and elastase enzymes, which are responsible for the collagen and elastin breakdown. In addition, molecular mechanisms of skin aging can induce inflammatory responses, which, in turn, results in upregulation of metalloproteinases (MMP-1, MMP-3, and MMP-9), contributing to the degradation of skin collagen and connective tissue $[23,24,28]$.

\subsection{Anti-Aging Activity}

As human beings age, the skin thins, dries, wrinkles and becomes pigmented. Skin aging is related to collagen fibers fragmentation by MMP-1 and increased mitochondrial ROS production and oxidative stress, resulting in common deletions of mitochondrial DNA. ROS production is known to cause the activation of: (i) AP-1, the transcription factor responsible for MMPs production; and (ii) nuclear transcription factor-kappa B (NF-kB), which is essential in normal physiology, however, an inappropriate regulation has been associated with several chronic diseases, inflammation and cancer $[23,28]$. NF-kB upregulates the transcription of pro-inflammatory mediators, such interleukin-1 (IL-1), IL-6, and IL-8, and tumor necrosis factor- $\alpha$ (TNF- $\alpha$ ). These pro-inflammatory mediators, in a positive feedback loop, stimulate further production of ROS and activate AP-1 and NF-kB, resulting in more damage and skin aging $[19,27,29]$.

As previously reported, CS have a high antioxidant content, especially chlorogenic acids and caffeine, two promising compounds for anti-wrinkle products. Recent research was developed on hyaluronidase inhibitory activity of CS extracts [20]. During aging, hyaluronic acid content diminishes and skin becomes dry and wrinkled. Indeed, hyaluronidase degrades hyaluronic acid, lowering its viscosity, increasing permeability, and leading to extracellular matrix (collagen and elastin fibers) destruction [30]. According to Furusawa et al. [20], the higher molecular-weight substances present in CS extracts could contribute to the hyaluronidase inhibition effect, with acidic polysaccharides (mainly composed by uronic acid) appearing to play a major role. In the cosmetics point of view, Rodrigues and colleagues [17] reported the skin compatibility and safety of CS extracts. In another study, Rodrigues et al. [18] performed an in vivo evaluation of hyaluronidase inhibitory effect. This assay was performed on 20 human volunteers, using a coffee silverskin-based cream, twice a day, over 28 days. After this period, the hydration and firmness was evaluated by comparing the cream containing CS with a formulation supplemented with 1.5\% of HyaCare ${ }^{\circledR}$ Filler CL (a cross-linked polysaccharide made from fermentation-derived hyaluronic acid). CS was shown to be an effective ingredient, with similar results to hyaluronic acid, in the improvement of skin hydration and firmness [18]. In two other studies [31,32], a body and a hand cream containing CS extract were developed. For both, antioxidant activity and consumer acceptability was high, and a viability cell decrease (in keratinocytes and fibroblasts) was not observed.

A new approach on anti-aging effect of CS extracts against accelerated aging caused by oxidative agents, was performed by Iriondo-DeHond et al. [33]. In this study, accelerated aging in C. elegans (animal model) was induced by ultraviolet radiation C (UVC) and in HaCaT cells (skin model) using tert-butyl hydroperoxide $(t-\mathrm{BOOH})$. The nematodes $C$. elegans treated with $\mathrm{CS}$ extract $(1 \mathrm{mg} / \mathrm{mL})$ showed a significant increased longevity compared to those cultured on a standard diet. The increased longevity observed was similar to that of the nematodes fed with chlorogenic acid or vitamin $C$ $(0.1 \mu \mathrm{g} / \mathrm{mL})$. On the other hand, the tested concentrations of CS extracts were not cytotoxic, and a CS extract of $1 \mathrm{mg} / \mathrm{mL}$ gave resistance to skin cells when oxidative damage was induced by $\mathrm{t}-\mathrm{BOOH}$. According to the authors, the anti-aging properties of CS may be due to its complex mixture of antioxidants that act in a synergistic combination [33]. In sum, CS extracts have the potential to be used as an ingredient in skin cosmetic product to reduce the production of intracellular ROS in keratinocytes and improving skin health. Additionally, as will be discussed later in Section 2.4, CS extracts protect against skin photoaging induced by UV radiation. 


\subsection{Anti-Inflammatory Activity}

Skin inflammation can be defined as a skin response to an injury, infection or destruction, normally characterized by heat, redness, pain, swelling or disturbed skin physiological functions. ROS contribute to pro-inflammatory signaling cascades and consequent production of cytokines such as interleukin-1 $\beta$ (IL-1 $\beta$ ), and TNF- $\alpha$ [29]. Importantly, there is reciprocal activation by oxidative stress and inflammatory mediators, since cytokines and TNF- $\alpha$ also induce $\mathrm{O}_{2}{ }^{\bullet-}$ production, activate or induce the expression of inflammatory enzymes (NOX2 and cyclooxygenase) and trigger NADPH oxidase-dependent inflammation. In addition, increase collagenase and/or elastase enzymes expression, decreasing the tensile strength and elasticity of the skin. Therefore, ROS, cytokines and interleukins act in synergism during the inflammatory skin process, inducing keratinocyte proliferation and monocyte recruitment to the injury side $[34,35]$.

Recent studies have evaluated the anti-inflammatory effect of chlorogenic acid (and its metabolite caffeic acid), a phenolic compound prevalent in CS composition [36]. In this study, the IL-8 production in a human intestinal cell line (Caco-2) was induced by combined stimulation with TNF- $\alpha$ and $\mathrm{H}_{2} \mathrm{O}_{2}$. The results demonstrated that cholorogenic acid and caffeic acid inhibit the induced IL-8 production, suggesting an important anti-inflammatory effect [36]. In turn, Hwang et al. [37] reported the caffeine anti-inflammatory effect on lipopolysaccharide (LPS)-induced inflammation. In that study, RAW264.7 cells were treated with several concentrations of caffeine in the presence or absence of LPS. The results showed a decrease in LPS-induced inflammatory mediators by regulating NF- $\mathrm{kB}$ activation [37].

Melanoidins are bioactive compounds that are formed during the coffee roast [22], and have also been found in CS (17-23\%) [9]. Important bioactive properties have been reported to this group of compounds as antioxidant activity, inhibition of MMPs, antimicrobial and anti-inflammatory activities [22]. Until now, only studies on coffee beans and coffee-based beverages have reported the melanoidins anti-inflammatory effect. Paur et al. [29] showed that extracts of dark-roasted coffee inhibit NF- $\mathrm{kB}$ activity by more than $80 \%$, in LPS-induced NF- $\mathrm{kB}$ activation. Similar evidences were reported by Vitaglione et al. [38] on reducing TNF- $\alpha$ expression.

\subsection{Antimicrobial Activity}

Rodrigues et al. [21] demonstrated the antimicrobial activity of CS extracts against pathogenic bacteria such as Staphylococcus aureus (ATCC 6538 and MRSA), Staphylococcus epidermidis, Escherichia coli (ATCC 1576 and MRSA) and Klebsiella pneumoniae (ATCC4352). In another study, Jiménez-Zamora and colleagues [39] show the prebiotic, antimicrobial and antioxidant capacity of CS, and highlighted the antimicrobial activity of melanoidins extracted from spent coffee grounds. Depending on their concentration, coffee melanoidins can have bacteriostatic or bactericide action. Their antimicrobial activity has been widely studied by different research groups [21,40]. In addition, other coffee compounds, naturally present in CS, as chlorogenic acids and caffeine [4], could synergistically interact for antibacterial activity against $S$. mutans, a microorganism related with dental plaque formation [41]. In sum, CS could have a promising application in skin infection diseases, or even as a preservative for final cosmetic formulations $[19,40]$.

\subsection{Protection against Skin UV Damage}

As previously reported in Section 2.2, skin inflammation can be a consequence of deleterious effects of extrinsic factors, being overexposure to UV solar radiation (mainly UVB) an important factor to skin-related disorders. UVB induces overproduction of ROS such as superoxide anion $\left(\mathrm{O}_{2}{ }^{\bullet-}\right)$ and singlet $\mathrm{O}_{2}\left({ }^{1} \mathrm{O}_{2}\right)$, which are critical events for the onset of oxidative stress conditions. For instance, $\mathrm{O}_{2}{ }^{\bullet-}$ reacts with hydrogen peroxide $\left(\mathrm{H}_{2} \mathrm{O}_{2}\right)$ generating the cytotoxic hydroxyl radical $\left({ }^{\bullet} \mathrm{OH}\right)$. In turn, - $\mathrm{OH}$ causes lipid peroxidation, a well-established detrimental consequence of UVB chronic exposure, evidenced by erythema, edema, hyperpigmentation, premature skin aging, and cancer. Exposure to UV light has an adverse effect on skin components such as elastin and collagen [23], eventually leading 
to formation of wrinkles. The formation of cholesterol oxidation products through UV exposure (by generation of an excited singlet oxygen that reacts with the double bond in position 5,6 of the B ring, following similar oxidative pathways as monounsaturated fatty acids) has also been reported [42].

In fact, increased ROS production induces inflammatory cytokines secretion and enhances dermal fibroblast MMPs levels, and decrease the procollagen synthesis. Expression of MMPs leads to degradation of extracellular matrix proteins (e.g., collagen and elastin fibers, fibronectin, and laminin), resulting in skin elasticity decrease and wrinkle formation [34]. Considering the synergic effect of ROS and inflammatory mediators, the use of compounds with antioxidant and anti-inflammatory effects are a promising approach to inhibit UVB irradiation-induced skin damage. In this context, a high attention has been paid to antioxidants from natural sources and their advantages (i.e., naturally occurring agents are considered to be less toxic and can be more economic). In this context, a new approach on sunscreens based in natural sources of antioxidants and anti-inflammatory compounds have been under development. Kitagawa et al. [43] evaluated the chlorogenic acid activity on skin protection against UV-induced damage. An oil/water product containing this compound was incubated on excised guinea pig dorsal skin and Yucatan micro pigskin. Antioxidant activity of chlorogenic acid was observed by ROS reduction, suggesting the potential of this compound to protect skin against UV-induced oxidative damage. While there are more than 25 types of MMPs, UV light exposure is particularly associated with induction of MMP-1, MMP-3, and MMP-9, which play critical roles in the skin aging process [44]. Recently, the potential effect of compounds isolated from Coffea arabica beans against UV-B induced skin damage was evaluated by Cho et al. [45]. The results evidenced individual anti-wrinkle effects of chlorogenic acid, pyrocatechol, and 3,4,5-tricaffeoyl quinic acid against UV-B stimulated mouse fibroblast cells (CCRF), by measuring expression levels of MMP-1, MMP-3, MMP-9, and type-I procollagen. Chlorogenic acid effectively suppressed the expression of the MMP-1, MMP-3, and MMP-9 and has potential to upregulate procollagen synthesis in UV-induced fibroblasts, which could be effective to reduce photoaging that leads to wrinkle formation. Additionally, chlorogenic acid presents a good sun protection factor (SPF) - a factor that measures the capacity of a compound to absorb UV radiation-and in vitro DNA protective effect. This study indicates that this phenolic compound has potential to be used as a preventive agent against premature skin aging induced by UV radiation [45]. Although this study was performed in coffee beans, chlorogenic acid is also the major phenolic in CS (1-6\%).

Caffeine is another natural compound of CS with UV-absorption properties. Lu and colleagues [46] studied the effect of caffeine topical application to prevent UVB-induced skin-cancer development on SKH-1 hairless mice. The mouse models were treated topically with caffeine once a day (five days/week) for 18 weeks, and the results showed that topical applications of caffeine decreased the number of nonmalignant and malignant skin tumors per mouse (44\% and $72 \%$, respectively). In another study, Koo and collaborators [47] evaluated the effect of topical application of caffeine in SKH-1 hairless mice skin after being exposed to UVB (three times/week for 11 weeks). Caffeine application promoted the deletion of DNA-damaged keratinocytes, suggesting that it may diminish photodamage and photocarcinogenesis. In addition, topical application of caffeine 30 minutes before a high dose UVB exposure showed a protective effect against sunburn lesions [47]. Recently, Choi et al. [48] evaluated the protective action of oil fraction (containing $547.32 \mathrm{mg} / \mathrm{mL}$ of caffeine and $119.25 \mathrm{mg} / \mathrm{mL}$ of chlorogenic acid) and ethanolic extracts (42.58 and $50.75 \mathrm{mg} / \mathrm{mL}$, respectively) of spent coffee grounds (from instant coffee). Topical application of the oil or ethanol fraction significantly reduced the UVB-induced wrinkle formation in mice dorsal skin. In addition, the combined application of oil and ethanolic fraction led to a decrease in the wrinkle area by over $35 \%$, epidermal thickness $(40 \%)$, transdermal water loss (27\%) and erythema formation (48\%) that result from UVB exposure, when compared with the UVB-treated control. In addition, polarization-sensitive optical coherence tomography and antibody-based histological analyses showed that oil fraction and ethanolic extracts effectively suppressed the UVB-induced decrease in collagen content. The level of type 1 collagen in the combined oil/ethanol fraction group was enhanced by around $40 \%$ compared with the UVB control 
group. A decrease in UVB-induced intracellular ROS production, and MMP-2 and MMP-9 expression was observed, in comparison with irradiated control cells. Not excluding other compounds, caffeine seems to be a major active compound in the protection against skin UV damage. The results of this study suggest the potential topical application of high caffeine level products as an anti-photoaging agent [48].

\subsection{Anti-Cellulite Activity}

Cellulite is a skin disorder that affects around $85 \%$ to $98 \%$ of women. Developed on body areas that contain subcutaneous adipose tissue (upper outer thighs, posterior thighs and buttocks), cellulite is usually known as "orange peel" due to the appearance caused by the herniation of subcutaneous adipose tissue [49]. According to Rawlings [50], cellulite is a multifactorial and complex condition that involves not only subcutaneous fat but also microcirculation and the lymphatic system. Due to their lipolytic effects, caffeine gains increasing interest as a cosmetic ingredient, particularly for gynoid lipodystrophy (commonly known as cellulite). Inhibiting phosphodiesterase in adipocytes and inducing cyclic adenosine monophosphate (cAMP), caffeine could exert lipolytic activity. An increase in cAMP levels stimulates the protein kinase A to phosphorylate, and consequently activates hormone-sensitive lipase. Phosphorylated, hormone-sensitive lipase hydrolyzes triglycerides into di- and monoglycerides, free fatty acids, and glycerol. Caffeine can penetrate the skin barrier and exert its lipolytic activity in adipose tissue. CS contains a significant amount of caffeine (comparable to arabica coffee beans) [51] and, in this context, it can be used to develop anti-cellulite topical products [52]. Indeed, Rodrigues et al. [53] suggests that caffeine extracted from CS can be used in a new possible therapy for cellulite.

\subsection{Anti-Hair Loss Activity}

Caffeine has been increasingly required for cosmetics production, not only to improve the skin's appearance but also the hair's condition due to its $5 \alpha$-reductase inhibition activity. This enzyme converts testosterone into the more active dihydrotestosterone (DHT), which is responsible for baldness due to the hair follicles sensitivity to DHT action. Caffeine, by inhibiting $5 \alpha$-reductase activity, renews the hair growth phase [50]. Indeed, a study of Fischer et al. [54] showed that caffeine concentrations ranging from $0.001 \%$ to $0.005 \%$ led to in vitro stimulation of human hair follicle growth. The stimulating effects of caffeine on hair growth can also be explained due to the caffeine phosphodiesterase inhibition activity with consequent increase of cAMP intracellular concentration and stimulating cellular metabolism [54]. In addition, caffeine reduces smooth muscle tension near the hair follicle causing an easier delivery of nutrients. Caffeine also arouses capillary vessel microcirculation in the head skin, thereby contributing to nurture hair bulbs. Teichmann et al. [55] and Lademann et al. [56] demonstrated that a 2-min contact of a shampoo with caffeine was sufficient for the formulation to penetrate deeply into the hair follicles and remain there for up to $48 \mathrm{~h}$, even after washing the hair. Otberg et al. [57] showed that there is a quantitative distinction between follicular penetration and interfollicular diffusion of a formulation containing $2.5 \%$ caffeine applied to the chest of male Caucasian volunteers aged 26-39 with normal body mass indices. When the follicles remained open, caffeine was detected in blood samples $5 \mathrm{~min}$ after topical application. In turn, when the follicles were blocked, caffeine was only detectable after $20 \mathrm{~min}$. The highest values (11.75 ng caffeine $/ \mathrm{mL}$ ) were found $1 \mathrm{~h}$ after application, when the follicles were open. The ability of caffeine to penetrate the hair follicles and to stimulate the human hair growth in vitro may have an important clinical impact on the management of androgenetic alopecia, a common problem in men of all ages. However, as far as we know, although CS contains caffeine (0.8-1.25\%), no study has focused on its potential to be used in cosmetics for hair loss. 


\section{Safety and Toxicity}

CS seems to be generally safe for use in the cosmetic field. Indeed, Rodrigues and colleagues [17] reported the skin compatibility and safety of CS extracts for topical application. This study, performed with in vitro skin and ocular irritation assays using reconstructed human epidermis (EpiSkin) and a human corneal epithelial model (SkinEthics HCE), respectively, showed that CS extracts were not irritant. Moreover, a histological analysis proved that both model structures were not affected after exposure to the CS extracts. The authors also described an in vivo assay to ensure the safety of a hydroalcoholic extract: a patch test was performed using 20 volunteers during a period of $48 \mathrm{~h}$, after which no skin irritant effects were observed [17]. In addition, other studies [31,32] report that the keratinocytes and fibroblasts viability was not affected due to the inclusion of CS in cream preparations, and no cytotoxic effects were found.

\section{Conclusions}

CS is a coffee roasting by-product, produced in large amounts every year. Its use can be seen as a gain not only for human health, but also to the environment and industries, answering to the principles of sustainability and circular economy.

Skin aging is a complex process associated to oxidative metabolism and reactive oxygen species (ROS) generation. Silverskin is a promising matrix that can answer to the new fields of cosmetic industry on natural active ingredients that improve health skin appearance, counteract skin aging and related diseases, in an environmentally eco-friendly approach.

One concern can be the presence of OTA (produced by Aspergillus ochraceus and Penicillium verrucosum) in CS. Nevertheless, good practices of coffee harvesting, storage, and transport (especially related with moisture and temperature exposure) and a rigorous quality control could minimize the presence of this micotoxin.

Due to CS richness in specific bioactive compounds (chlorogenic acids (1-6\%), caffeine (0.8-1.25\%), and melanoidins (17-23\%), among other antioxidants) and confirmed bioactivity in the prevention and/or attenuation of skin aging and related diseases (anti-inflammatory, antimicrobial, anti-cellulite, and anti-hair loss activities, and UV damage protection), CS and its extracts emerge as potential new ingredients for the cosmetics formulation sector.

Acknowledgments: The authors thank the financial support to the project Operação NORTE-01-0145-FEDER000011 - denominada Qualidade e Segurança Alimentar-uma abordagem (nano)tecnológica. This work was also supported by the project UID/QUI/50006/2013-POCI/01/0145/FEDER/007265 with financial support from FCT/MEC through national funds and co-financed by FEDER. S.M.F. Bessada acknowledges the PhD fellowship (SFRH/BD/122754/2016) funded by FCT.

Conflicts of Interest: The authors declare no conflict of interest.

\section{References}

1. Alves, R.C.; Rodrigues, F.; Antónia Nunes, M.; Vinha, A.F.; Oliveira, M.B.P.P. State of the art in coffee processing by-products. In Handbook of Coffee Processing by-Products, 1st ed.; Galanakis, C.M., Ed.; Academic Press: London, UK, 2017; pp. 1-26.

2. Borrelli, R.C.; Esposito, F.; Napolitano, A.; Ritieni, A.; Fogliano, V. Characterization of a new potential functional ingredient: Coffee silverskin. J. Agric. Food Chem. 2004, 52, 1338-1343. [CrossRef] [PubMed]

3. Costa, A.S.; Alves, R.C.; Vinha, A.F.; Costa, E.; Costa, C.S.; Nunes, M.A.; Almeida, A.A.; Santos-Silva, A.; Oliveira, M.B.P.P. Nutritional, chemical and antioxidant/pro-oxidant profiles of silverskin, a coffee roasting by-product. Food Chem. 2017. [CrossRef]

4. Costa, A.S.; Alves, R.C.; Vinha, A.F.; Barreira, S.V.; Nunes, M.A.; Cunha, L.M.; Oliveira, M.B.P.P. Optimization of antioxidants extraction from coffee silverskin, a roasting by-product, having in view a sustainable process. Ind. Crops Prod. 2014, 53, 350-357. [CrossRef] 
5. Carneiro, L.; Silva, J.; Mussatto, S.; Roberto, I.; Teixeira, J. Determination of total carbohydrates content in coffee industry residues. In Book of Abstracts of the 8th International Meeting of the Portuguese Carbohydrate Group; GLUPOR: Braga, Portugal, 2009; p. 94.

6. Napolitano, A.; Fogliano, V.; Tafuri, A.; Ritieni, A. Natural occurrence of ochratoxin A and antioxidant activities of green and roasted coffees and corresponding byproducts. J. Agric. Food Chem. 2007, 55, 10499-10504. [CrossRef] [PubMed]

7. Toschi, T.G.; Cardenia, V.; Bonaga, G.; Mandrioli, M.; Rodriguez-Estrada, M.T. Coffee silverskin: Characterization, possible uses, and safety aspects. J. Agric. Food Chem. 2014, 62, 10836-10844. [CrossRef] [PubMed]

8. Alves, R.C.; Costa, A.S.; Jerez, M.A.; Casal, S.; Sineiro, J.; Núñez, M.J.; Oliveira, M.B.P.P. Antiradical activity, phenolics profile, and hydroxymethylfurfural in espresso coffee: Influence of technological factors. J. Agric. Food Chem. 2010, 58, 12221-12229. [CrossRef] [PubMed]

9. Mesías, M.; Navarro, M.; Martínez-Saez, N.; Ullate, M.; del Castillo, M.; Morales, F. Antiglycative and carbonyl trapping properties of the water soluble fraction of coffee silverskin. Food Res. Int. 2014, 62, 1120-1126. [CrossRef]

10. Iriondo-DeHond, A.; Haza, A.I.; Ávalos, A.; del Castillo, M.D.; Morales, P. Validation of coffee silverskin extract as a food ingredient by the analysis of cytotoxicity and genotoxicity. Food Res. Int. 2017, 100, 791-797. [CrossRef] [PubMed]

11. European Commission. Commission Regulation (EC) No. 123/2005 of 26 January 2005 amending Regulation (EC) No. 466/2001 as regards ochratoxin A. Off. J. Eur. Union 2005, L25, 3-5.

12. Narita, Y.; Inouye, K. Review on utilization and composition of coffee silverskin. Food Res. Int. 2014, 61, 16-22. [CrossRef]

13. Ballesteros, L.F.; Teixeira, J.A.; Mussatto, S.I. Selection of the solvent and extraction conditions for maximum recovery of antioxidant phenolic compounds from coffee silverskin. Food Bioproc. Technol. 2014, 7, 1322-1332. [CrossRef]

14. Mussatto, S.I.; Machado, E.M.; Martins, S.; Teixeira, J.A. Production, composition, and application of coffee and its industrial residues. Food Bioprocess Technol. 2011, 4, 661-672. [CrossRef]

15. Pourfarzad, A.; Mahdavian-Mehr, H.; Sedaghat, N. Coffee silverskin as a source of dietary fiber in bread-making: Optimization of chemical treatment using response surface methodology. LWT-Food Sci. Technol. 2013, 50, 599-606. [CrossRef]

16. Martinez-Saez, N.; Ullate, M.; Martin-Cabrejas, M.A.; Martorell, P.; Genovés, S.; Ramon, D.; del Castillo, M.D. A novel antioxidant beverage for body weight control based on coffee silverskin. Food Chem. 2014, 150, 227-234. [CrossRef] [PubMed]

17. Rodrigues, F.; Pereira, C.; Pimentel, F.; Alves, R.; Ferreira, M.; Sarmento, B.; Amaral, M.H.; Oliveira, M.B.P.P. Are coffee silverskin extracts safe for topical use? An in vitro and in vivo approach. Ind. Crops Prod. 2015, 63, 167-174. [CrossRef]

18. Rodrigues, F.; Matias, R.; Ferreira, M.; Amaral, M.H.; Oliveira, M.B.P.P. In vitro and in vivo comparative study of cosmetic ingredients coffee silverskin and hyaluronic acid. Exp. Dermatol. 2016, 25, 572-574. [CrossRef] [PubMed]

19. Rodrigues, F.; Antónia Nunes, M.; Alves, R.; Oliveira, M. Applications of recovered bioactive compounds in cosmetics and other products. In Handbook of Coffee Processing by-Products, 1st ed.; Galanakis, C.M., Ed.; Academic Press: London, UK, 2017; pp. 195-220.

20. Furusawa, M.; Narita, Y.; Iwai, K.; Fukunaga, T.; Nakagiri, O. Inhibitory effect of a hot water extract of coffee "silverskin" on hyaluronidase. Biosci. Biotechnol. Biochem. 2011, 75, 1205-1207. [CrossRef] [PubMed]

21. Rodrigues, F.; Palmeira-de-Oliveira, A.; das Neves, J.; Sarmento, B.; Amaral, M.H.; Oliveira, M.B.P.P. Coffee silverskin: A possible valuable cosmetic ingredient. Pharm. Biol. 2015, 53, 386-394. [CrossRef] [PubMed]

22. Moreira, A.S.; Nunes, F.M.; Domingues, M.R.; Coimbra, M.A. Coffee melanoidins: Structures, mechanisms of formation and potential health impacts. Food Funct. 2012, 3, 903-915. [CrossRef] [PubMed]

23. Lephart, E.D. Skin aging and oxidative stress: Equol's anti-aging effects via biochemical and molecular mechanisms. Ageing Res. Rev. 2016, 31, 36-54. [CrossRef] [PubMed]

24. Berthon, J.-Y.; Nachat-Kappes, R.; Bey, M.; Cadoret, J.-P.; Renimel, I.; Filaire, E. Marine algae as attractive source to skin care. Free Rad. Res. 2017, 51, 555-567. [CrossRef] [PubMed] 
25. Pisoschi, A.M.; Pop, A. The role of antioxidants in the chemistry of oxidative stress: A review. Eur. J. Med. Chem. 2015, 97, 55-74. [CrossRef] [PubMed]

26. Bessada, S.M.; Barreira, J.C.; Oliveira, M.B.P.P. Asteraceae species with most prominent bioactivity and their potential applications: A review. Ind. Crops Prod. 2015, 76, 604-615. [CrossRef]

27. Del Castillo, M.; Fernandez-Gomez, B.; Martinez Saez, N.; Iriondo De Hond, A.; Martirosyan, D.; Mesa, M. Coffee silverskin extract for aging and chronic diseases. In Functional Foods for Chronic Diseases, 1st ed.; Martirosyan, D.M., Ed.; CreateSpace Independent Publishing Platform: Colorado, TX, USA, 2016; pp. 386-409.

28. Tobin, D.J. Introduction to skin aging. J. Tissue Viability 2017, 26, 37-46. [CrossRef] [PubMed]

29. Paur, I.; Balstad, T.R.; Blomhoff, R. Degree of roasting is the main determinant of the effects of coffee on NF-kb and epre. Free Radic. Biol. Med. 2010, 48, 1218-1227. [CrossRef] [PubMed]

30. Sahasrabudhe, A.; Deodhar, M. Anti-hyaluronidase, anti-elastase activity of Garcinia indica. Int. J. Bot. 2010, 6,1-10. [CrossRef]

31. Rodrigues, F.; Gaspar, C.; Palmeira-de-Oliveira, A.; Sarmento, B.; Helena Amaral, M.; Oliveira, M.B.P.P. Application of coffee silverskin in cosmetic formulations: Physical/antioxidant stability studies and cytotoxicity effects. Drug Dev. Ind. Pharm. 2016, 42, 99-106. [CrossRef] [PubMed]

32. Rodrigues, F.; Sarmento, B.; Amaral, M.H.; Oliveira, M.B.P.P. Exploring the antioxidant potentiality of two food by-products into a topical cream: Stability, in vitro and in vivo evaluation. Drug Dev. Ind. Pharm. 2016, 42, 880-889. [CrossRef] [PubMed]

33. Iriondo-DeHond, A.; Martorell, P.; Genovés, S.; Ramón, D.; Stamatakis, K.; Fresno, M.; Molina, A.; del Castillo, M.D. Coffee silverskin extract protects against accelerated aging caused by oxidative agents. Molecules 2016, 21, 721. [CrossRef] [PubMed]

34. Martinez, R.M.; Pinho-Ribeiro, F.A.; Steffen, V.S.; Silva, T.C.; Caviglione, C.V.; Bottura, C.; Fonseca, M.J.; Vicentini, F.T.; Vignoli, J.A.; Baracat, M.M. Topical formulation containing naringenin: Efficacy against ultraviolet $\mathrm{b}$ irradiation-induced skin inflammation and oxidative stress in mice. PLoS ONE 2016, 11, e0146296. [CrossRef] [PubMed]

35. Menezes, A.C.; Campos, P.M.; Euletério, C.; Simões, S.; Praça, F.S.G.; Bentley, M.V.L.B.; Ascenso, A. Development and characterization of novel 1-(1-naphthyl) piperazine-loaded lipid vesicles for prevention of uv-induced skin inflammation. Eur. J. Pharm. Biopharm. 2016, 104, 101-109. [CrossRef] [PubMed]

36. Shin, H.S.; Satsu, H.; Bae, M.-J.; Zhao, Z.; Ogiwara, H.; Totsuka, M.; Shimizu, M. Anti-inflammatory effect of chlorogenic acid on the IL-8 production in Caco-2 cells and the dextran sulphate sodium-induced colitis symptoms in c57bl/ 6 mice. Food Chem. 2015, 168, 167-175. [CrossRef] [PubMed]

37. Hwang, J.-H.; Koh, E.-J.; Lee, Y.-J.; Chio, J.; Song, J.-H.; Seo, Y.-J.; Lee, B.-Y. Anti-inflammatory effect of caffeine by regulating NF-kb activation in murine macrophage. FASEB J. 2016, 30, lb256. Available online: http:/ / www.fasebj.org/content/30/1_Supplement/lb256.short (accessed on 3 January 2018).

38. Vitaglione, P.; Morisco, F.; Mazzone, G.; Amoruso, D.C.; Ribecco, M.T.; Romano, A.; Fogliano, V.; Caporaso, N.; D'argenio, G. Coffee reduces liver damage in a rat model of steatohepatitis: The underlying mechanisms and the role of polyphenols and melanoidins. Hepatology 2010, 52, 1652-1661. [CrossRef] [PubMed]

39. Jiménez-Zamora, A.; Pastoriza, S.; Rufián-Henares, J.A. Revalorization of coffee by-products. Prebiotic, antimicrobial and antioxidant properties. LWT-Food Sci. Technol. 2015, 61, 12-18. [CrossRef]

40. Rufian-Henares, J.A.; de la Cueva, S.P. Antimicrobial activity of coffee melanoidins: A study of their metal-chelating properties. J. Agric. Food Chem. 2009, 57, 432-438. [CrossRef] [PubMed]

41. Antonio, A.G.; Moraes, R.S.; Perrone, D.; Maia, L.C.; Santos, K.R.N.; Iório, N.L.; Farah, A. Species, roasting degree and decaffeination influence the antibacterial activity of coffee against streptococcus mutans. Food Chem. 2010, 118, 782-788. [CrossRef]

42. Cardenia, V.; Rodriguez-Estrada, M.T.; Boselli, E.; Lercker, G. Cholesterol photosensitized oxidation in food and biological systems. Biochimie. 2013, 95, 473-481. [CrossRef] [PubMed]

43. Kitagawa, S.; Yoshii, K.; Morita, S.-Y.; Teraoka, R. Efficient topical delivery of chlorogenic acid by an oil-in-water microemulsion to protect skin against UV-induced damage. Chem. Pharm. Bull. 2011, 59, 793-796. [CrossRef] [PubMed]

44. Quan, T.; Qin, Z.; Xia, W.; Shao, Y.; Voorhees, J.J.; Fisher, G.J. Matrix-degrading metalloproteinases in photoaging. J. Investig. Dermatol. Symp. Proc. 2009, 14, 20-24. [CrossRef] [PubMed] 
45. Cho, Y.-H.; Bahuguna, A.; Kim, H.-H.; Kim, D.-I.; Kim, H.-J.; Yu, J.-M.; Jung, H.-G.; Jang, J.-Y.; Kwak, J.-H.; Park, G.-H. Potential effect of compounds isolated from Coffea arabica against UV-B induced skin damage by protecting fibroblast cells. J. Photochem. Photobiol. B Biol. 2017, 174, 323-332. [CrossRef] [PubMed]

46. Lu, Y.-P.; Lou, Y.-R.; Xie, J.-G.; Peng, Q.-Y.; Liao, J.; Yang, C.S.; Huang, M.-T.; Conney, A.H. Topical applications of caffeine or (-)-epigallocatechin gallate (EGCG) inhibit carcinogenesis and selectively increase apoptosis in UVB-induced skin tumors in mice. Proc. Natl. Acad. Sci. USA 2002, 99, 12455-12460. [CrossRef] [PubMed]

47. Koo, S.W.; Hirakawa, S.; Fujii, S.; Kawasumi, M.; Nghiem, P. Protection from photodamage by topical application of caffeine after ultraviolet irradiation. Br. J. Dermatol. 2007, 156, 957-964. [CrossRef] [PubMed]

48. Choi, H.-S.; Park, E.D.; Park, Y.; Han, S.H.; Hong, K.B.; Suh, H.J. Topical application of spent coffee ground extracts protects skin from ultraviolet B-induced photoaging in hairless mice. Photochem. Photobiol. Sci. 2016, 15, 779-790. [CrossRef] [PubMed]

49. Alizadeh, Z.; Halabchi, F.; Mazaheri, R.; Abolhasani, M.; Tabesh, M. Review of the mechanisms and effects of noninvasive body contouring devices on cellulite and subcutaneous fat. Int. J. Endocrinol. Metab. 2016, 14, e36727. [CrossRef] [PubMed]

50. Rawlings, A. Cellulite and its treatment. Int. J. Cosmet. Sci. 2006, 28, 175-190. [CrossRef] [PubMed]

51. Alves, R.C.; Oliveira, M.B.P.P.; Casal, S. Coffee authenticty. In Current Topics on Food Authetication, 1st ed.; Oliveira, M.B.P.P., Mafra, I., Amaral, J.S., Eds.; Transworld Research Network: Kerala, India, 2017; pp. 57-72.

52. Herman, A.; Herman, A. Caffeine's mechanisms of action and its cosmetic use. Skin Pharmacol. Physiol. 2013, 26, 8-14. [CrossRef] [PubMed]

53. Rodrigues, F.; Alves, A.C.; Nunes, C.; Sarmento, B.; Amaral, M.H.; Reis, S.; Oliveira, M.B.P.P. Permeation of topically applied caffeine from a food by-product in cosmetic formulations: Is nanoscale in vitro approach an option? Int. J. Pharm. 2016, 513, 496-503. [CrossRef] [PubMed]

54. Fischer, T.; Hipler, U.; Elsner, P. Effect of caffeine and testosterone on the proliferation of human hair follicles in vitro. Int. J. Dermatol. 2007, 46, 27-35. [CrossRef] [PubMed]

55. Teichmann, A.; Richter, H.; Knorr, F.; Antoniou, C.; Sterry, W.; Lademann, J. Investigation of the penetration and storage of a shampoo formulation containing caffeine into the hair follicles by in vivo laser scanning microscopy. Laser Phys. Lett. 2007, 4, 464-468. [CrossRef]

56. Lademann, J.; Richter, H.; Schanzer, S.; Klenk, A.; Sterry, W.; Patzelt, A. Analysis of the penetration of a caffeine containing shampoo into the hair follicles by in vivo laser scanning microscopy. Laser Phys. 2010, 20, 551-556. [CrossRef]

57. Otberg, N.; Patzelt, A.; Rasulev, U.; Hagemeister, T.; Linscheid, M.; Sinkgraven, R.; Sterry, W.; Lademann, J. The role of hair follicles in the percutaneous absorption of caffeine. Br. J. Clin. Pharm. 2008, 65, 488-492. [CrossRef] [PubMed]

(C) 2018 by the authors. Licensee MDPI, Basel, Switzerland. This article is an open access article distributed under the terms and conditions of the Creative Commons Attribution (CC BY) license (http://creativecommons.org/licenses/by/4.0/). 